\title{
Introduktion
}

\section{Diagnoser: Organisation, kultur og mennesker}

Mikka Nielsen, Anders Petersen, Mette Bech Risør \& Mette Rønberg

Aalborg Universitet

mikka@hum.aau.dk

Aalborg Universitet

apt@socsci.aau.dk

UiT Norges Arktiske Universitet

mette.bech@uit.no

København og Aalborg Universitet

mro@hum.aau.dk

Nielsen, Mikka; Petersen, Anders; Risør, Mette Bech \& Rønberg, Mette (2016).

'Diagnoser: Organisation, kultur og mennesker' Tidsskrift for Forskning i Sygdom og Samfund, nr. 25, 5-13

Der er rav i den. I skrivende stund (medio september 2016) er det i Dagbladet Information kommet frem, at psykiatriske diagnoser til børn nogle gange stilles på et meget løst grundlag. I en kronik underskrevet af 50 psykologer, sygeplejersker, læger og psykiatere står der blandt andet:

»Som læger og psykologer har vi stillet diagnoser på børn på baggrund af andres vurderinger beskrevet kort $i$ patientens journal, og andre gange har barnet mødt mange forskellige behandlere på sin vej til en diagnose. Mange af disse børn er i forvejen sårbare i forhold til at danne nye relationer, og de bliver mødt af en psykiatri, hoor der ikke længere er mulighed for at skabe den relation, der skal til for at forstå barnet.«

Nogle børn har, med andre ord, fået stillet en diagnose, uden at de har mødt en læge, psykolog eller psykiater. Det får naturligt nok debatten til at rase. I relation 
til den verserende debat er fokus for dette nummer særligt rettet imod tre forhold: Den politisk fastsatte udrednings- og behandlingsgaranti. Den organisatoriske ramme skal kunne håndtere denne garanti, og selve den måde hvorpå diagnoserne stilles. Baggrunden for behandlingsgarantien er først og fremmest et politisk ønske om hurtigt at stille diagnoser, så patienten kan indgå i et behandlingsforløb - i sig selv et sympatisk ønske, der dog løber ind i en række problemer og utilsigtede konsekvenser, når den skal eksekveres i praksis, som det fremgår af lægernes debatindlæg. Et centralt omdrejningspunkt for de ophedede diskussioner, som avisindlæggene har medført - og som allerede nu har fået politiske konsekvenser - er samtidens omgang med, forståelse- og brug af diagnoser. Diagnoser er på alles læber for tiden. Diagnoser har, som den amerikanske medicinhistoriker Charles Rosenberg skriver, "altid spillet en væsentlig rolle i den medicinske praksis" (Rosenberg 2002: 237) som et værktøj/model, der sammenfatter symptomer og fund og angiver behandling. I vores samtid er diagnoserne imidlertid rejst ud af den medicinske praksis, og de har indlejret sig i alle mulige andre sammenhænge: Sociale, politiske, økonomiske, kulturelle og så videre. Et væsentligt spørgsmål i denne sammenhæng er, hvordan vi skal forstå diagnosernes nuværende status, hvordan de tillægges mening, udvikles, defineres, anvendes, og hvordan diagnoser får indflydelse på konkrete sygdomsforhold og på processer generelt, som spiller ind på, hvordan vi opfatter sundhed, krop og behandling.

Med dette temanummer ønsker Tidsskrift for Forskning i Sygdom og Samfund, at fokusere på fænomenet diagnoser og måden de forstås og benyttes i samtiden. Artiklerne, som er skrevet af sociologer, antropologer, psykologer, læger og forskere i socialt arbejde, spænder bredt og giver læserne en mulighed for at komme vidt omkring i diagnosernes verden - eller måske vi skulle skrive mulighed for at komme rundt i den verden, som diagnoserne i stadig større grad gør sit indtog i.

\section{Diagnosekultur}

En del af forfatterne til denne introduktion, Nielsen, Toft Rønberg og Petersen, har igennem en periode på 3,5 år været med i forskningsgruppen Diagnostic Culture. Omdrejningspunktet for projektet er begrebet 'diagnosekultur', der netop kan sige noget om diagnosers ændrede status i samtiden. Begrebet referer til en kultur, som er kendetegnet ved, at psykiatriske diagnoser og kategorier cirkulerer i den og ikke alene benyttes af fagpersoner (læger, psykologer, psykiatere osv.), men også af lægmænd og offentligheden til at begribe tilværelsens problemer, lidelse 
og menneskelig afvigelse (Brinkmann og Petersen 2015: 7-8). Diagnosekulturen materialiserer sig på flere områder: I det stigende antal mennesker, der får psykiatriske diagnoser; i relation til dagligdagsproget, hvor det diagnostiske sprog glider ind i og anvendes til forståelse af mange forskellige livsfænomener; og i forhold til de mange nye psykiatriske diagnoser, der løbende skabes og tillægges betydning. Den røde tråd, der løber igennem diagnosekulturen, har derfor sit fundament i en særlig psykiatrisk logik. Her dominerer symptomer på psykiske lidelser, alt imens deres ætiologiske forhold optræder som inferiøre. Summa summarum: Diagnosekulturen gennemsyres af et særligt psykiatrisk blik på menneskelig lidelse og afvigelse. Det blik udvisker måske ikke andre forståelser, der tidligere har haft større betydning. Men det overskygger dem. På mange måder synes det sociale, psykologiske, eksistentielle, religiøse, politiske og moralske sprog - og sikkert også andre - at være blevet overhalet og skubbet i baggrunden til fordel for det psykiatriske (Brinkmann 2014).

Samtidig hermed har det psykiatrisk funderede diagnosesprog opnået en særlig magt, blandt andet med hensyn til at indkredse og definere menneskeligt ubehag og livsproblemer, men også i socioøkonomisk og politisk forstand: Diagnoser anvendes i moderne velfærdsstater som reguleringsmekanisme i forhold til tildeling af privilegier og ressourcer - herunder adgang til orlov, pensioner, behandling og legitim sygdomsadfærd. På mange socialretslige områder anvendes diagnoser eksempelvis i kommunerne som adgangsbillet til diverse ydelser og støtte. Diagnosekulturen har med andre ord væsentlige samfundsmæssige implikationer - og det samme gør sig gældende på individniveau. I diagnosekulturen synes menneskers oplevelse af lidelse i stadig større udstrækning at blive filtreret gennem psykiatriske diagnosekategorier, ligesom det også gør sig gældende i forhold til spørgsmål om identitet, krop, seksualitet og selvforhold (Brinkmann \& Petersen 2015).

I dette temanummer diskuterer vi forudsætninger for og konsekvenserne af diagnosekulturen. Og selvom begrebet diagnosekultur primært er rettet imod og anvendt i forhold til - psykiatriske diagnoser, rejser spørgsmålet sig, om begrebet ikke også kan gøre sig analytisk gældende i forhold til somatiske diagnoser? Udviklingen indenfor en lang række somatiske områder synes nok at vidne om, at diagnosekulturen også har indlejret sig der. Med den teknologiske udvikling er det blevet muligt at finde abnormiteter, der i epidemiologiske undersøgelser kan kobles til større sygelighed og død. Grænserne for det normale ændres, som det for eksempel er sket med diagnosen diabetes. Teknologien tillader også at påvise ændringer og tilstande i kroppen på stadig tidligere stadier (Reventlow et 
al 2008). Der tales om prædiagnoser og risikodiagnoser (Reventlow et al 2006). Derved vil meget få mennesker kunne undgå at få en diagnose, og jo ældre du er jo flere diagnoser. Store dele af medicinen og mange sundhedsprofessionelle forskere tænker også kritisk om diagnoser, hvad enten de er psykiatriske eller somatiske. Nylige debatter sætter eksempelvis multimorbiditet, patienter med flere samtidige diagnoser på dagsorden, hvor de dermed angriber diagnosesystemets funktionalitet og mangel på patientcentrerethed (Willadsen et al). Andre diskuterer 'overdiagnostik' og kobler dette med de mange risikodiskurser, som har indflydelse på overdiagnostik. Man undersøger også kritisk, hvordan et fokus på biodata/monitoreringsteknologier, screening, stigning i kliniske tests med videre både definerer diagnoser ind i et teknologisk domæne og skaber nye diagnostiske kategorier. Som et konkret eksempel kan nævnes bogen 'Diagnosis', som er et samarbejde mellem forskere i almenmedicin og 'medical humanities' (Ahlzén et al 2010), hvor bidragsyderne især forholder sig til udfordringen mellem den enkelte patients særegne, unikke liv og mødet med lægens diagnosepraksis. Her er det klinikken, der er i centrum og patientens fortællinger, den intersubjektive relation mellem læge og patient, hvad diagnoser betyder og får betydning for - alt sammen i lyset af at diagnoser ikke skal tages for givet, men er til forhandling og under forandring - også set fra et medicinsk perspektiv.

\section{En sociologi om diagnoser}

Inden for de humanistiske og samfundsvidenskabelige discipliner har man længe undersøgt diagnosers status og anvendelse, og diagnoser har haft en væsentlig plads i analyser af det medicinske felts udvikling og samfundsmæssige indlejring. Dog er det ikke før for nylig, at en specifik gren indenfor sociologien har viet hele sit analytiske genstandsfelt til diagnoser. Sociology of Diagnosis - i mangel på bedre oversættelse, En sociologi om diagnoser (Petersen 2015) - så dagens lys i 2009, da Annemarie Jutel lancerede den (Jutel 2009). Før Jutel, hvis overordnede tanker vi nok skal vende tilbage til, havde Phil Brown opfordret til sociologiske analyser af diagnoser, som ikke blev underlagt medikaliseringskategorien, som det ellers tidligere var kutyme (Brown 1990). Cirka tyve år efter var tiden moden til en sociologi om diagnoser, hvis primære formål er - som det står beskrevet i en antologi med titlen Sociology of Diagnosis - at anerkende diagnoser "as a topic worthy of study in its own right" (Anspach 2011: xiv). Jutels udgangspunkt er, at diagnoser har indtaget så væsentlig en samfundsmæssig plads, at de uden videre 
kan bære at være analytisk omdrejningspunkt for sociologisk - men også for andre samfundsvidenskabelige og humanistiske discipliners - granskning. Diagnoser forbindes med områder som sundhed, sygdom, normalitet, stigmatisering, identitet, social kontrol, magt, sundhedsuddannelse og så videre, og de er derfor centrale emner i en sociologi om diagnoser. I lanceringen af den nye sociologiske gren pointerer Jutel, at ingen forrang for mikro, meso eller makro aspekter af diagnoser forefindes. De personlige, organisatoriske og samfundsmæssige/strukturelle anknytninger til diagnoser er i analytisk forstand lige vigtige. Som hun skriver: "Mange strukturer, agenter og handlinger entrerer den diagnostiske arena og fortjener omtanke” (Jutel 2011: 27). Derfor muliggør og opfordrer disciplinen til en bred vifte af historiske, empiriske og teoretiske nedslag, som forskeren kan foretage. I antologien Sociology of Diagnosis vises den mangfoldighed af muligheder, som perspektivet lægger op til. Heri forefindes artikler om alt fra perspektivets adskillelse fra medikaliseringstesen; diagnosernes historiske opkomst; konsekvensen af, at visse diagnoser slettes fra de diagnostiske manualer, og hvad det betyder for menneskers identitetskonstruktion; komplicerede diagnosers påvirkning på dem, der får dem stillet; diagnosers stigmatiserende effekter; diagnoser som social kontrol og så videre (McGann \& Hutson 2011). Den liste er naturligvis ikke udtømmende - der synes altså at være behov for endnu mere forskning på området.

Den medicinske antropologiske forskning på feltet overlapper med sociologiens, men er måske i højere grad dekonstruktivistisk i sin tilgang og interesseret i udviklingen af diagnoser som videnskategori. Et tidligt bidrag her stammer fra Patricia Kaufert som blotlægger biomedicinens procedure og ræsonnementer i forbindelse med udviklingen af en særlig diagnose, menopausen. Kaufert viser, hvordan der er en klar diskrepans mellem hverdagslivets erfaringer med ophør af menstruation og de kliniske definitioner og ræsonnementer, som fører til klassifikationen (Kaufert 1988). I dag har dette paralleller til kritiske analyser af klassifikationssystemer som DSM IV og 5, og det er med til at relativisere og problematisere diagnoser som depression og ADHD. Flere forskere har givet eksempler på konstruktionen af sygdomskategorier, af diagnoser og på produktionen af diagnostisk evidens inden for medicin (Aronowitz 1998, 2001, Davies 2016). Også i kølvandet af teknologiske landvindinger, screeningsprogrammer, genetisk rådgivning med videre hvor landskabet ændrer sig for både patienter og sundhedsprofessionelle, får vi analyser af nye grænseflader for diagnostik, patienters og pårørendes udfordringer med at forstå og tilegne sig eller modulere en diagnose uden for eksempel at føle sig syg og eventuelt befinde sig 'at risk' for noget, som allerede er en pre-diagnose i medicinsk forstand. Her får beretninger om personlige 
oplevelser og kropslige erfaringer med diagnoser ny analytisk opmærksomhed i lyset af ændrede teknologiske, sociale og kulturelle betingelser såsom hjemmeteknologi, digital sundhed og kropsmonitorering.

Antropologiens bidrag til diagnoseforskning er således på den ene side præget af ønsket om netop at vise, hvordan diagnoser 'laves' som videnskabelig klassifikation og ud fra medicinens rationaler. I hvert fald er dette i tråd med en interesse for videnssystemer og biomedicinen som et kulturelt system, hvor det netop er medicinens udøvere, der kan forskes på. Annemarie Mol er eksempelvis optaget af, hvordan diagnoser bliver 'udøvet' (enacted) og praktiseret, og hun har skrevet detaljerede analyser af 'doing disease' i forbindelse med udøvelsen/bestemmelsen af forskellige kategorier for arterosklerose, både i lægens praksis, men også i samspil med patienten (Mol 2002). Flere analyser af hvordan sundhedsprofessionelle udøver, bruger og anvender/modulerer diagnoser i hverdagsklinikken, vil givet være vigtige bidrag til forskning i diagnosekulturen. På den anden side er antropologisk forskning ikke alene 'science research', men det er også grundlæggende etnografiske studier af forskellige diagnostiske kategorier og processer, for eksempel hvordan diagnoser 'rejser' og approprieres/indlejres i forskellige sociale og kulturelle kontekster med stor vægt på et bottom-up perspektiv og fyldige hverdagsbeskrivelser om diagnostiske processer. Det bringer os ind på blandt andet forskning på patienten eller andre ikke-sundhedsprofessionelle, som involverer sig i diagnostisk arbejde. Diagnoser florerer som nævnt udenfor kliniske settings, og lige så vigtigt er det her at forstå, hvad eksempelvis selvdiagnoser er, og hvordan de konstitueres, eller hvordan nye konfigurationer for patientens diagnostiske forhandlinger og processer udvikles i tæt samspil med medicinens udvikling (Andersen 2014). På en nylig konference om 'Configurations of diagnostic processes, practices and evidence' (MAAH IX Tromsø 2016) var netop grænsesnittet mellem klinik/ikke klinik et omdrejningspunkt, som mange havde udfoldet, og som gav indblik i væsentlige etnografiske beskrivelser af patienters, pårørendes, organisationers 'arbejde' med diagnoser - en konstant subjektiviseringsprocess som er vigtig at beskrive ud fra de mange nye biopolitiske og medicinske arenaer. Samtidig pegede konferencen på nye veje som for eksempel at anvende analytiske termer såsom affektive praksisser og emotionelt arbejde begreber, som tilføjer en anden dimension til analyser af diagnoseprocesser end tidligere, og som åbnede for en ny måde at understrege på, at diagnoser ikke skal tages for givet, men er underlagt mange forskellige rationaler. I en nylig antologi, 'Diagnostic Controversy' (Smith-Morris 2016), præsenteres antropologiske analyser af især sygdomstilstande, som er kontroversielle, usikre og til forhandling, set 
fra patientens side, men også set i konteksten af global sundhed, medikalisering og sundhedsssystemers udforming. Især udgangspunktet at 'diagnosis hovers at the edge of scientific certainty' præger den kritiske tilgang til diagnoser i denne antology.

Som dette temanummer også vidner om, så er indgangen til studiet af diagnoser meget bred. Og det skal den også være, fordi emnet er mangefacetteret. Fra personlige fortællinger om tilværelsen med diagnoser over organisatoriske omgange med diagnoser til de samfundsmæssige betingelser for diagnosernes indtog i tiden.

\section{Temanummerets artikler}

I temanummerets første artikel "Where does a diagnosis come from? Questions about the local context in diagnostic reasoning" undersøger Torsten Risør, hvordan klinisk beslutningstagning i henholdsvis en afdeling for intern medicin og kirurgi er influeret af den kliniske og sociale kontekst. Baseret på sit feltarbejde på de to afdelinger argumenterer Risør for, at læger anvender en kombination af, hvad han kalder "a local spectrum of normality", hurtige beslutningsveje og forskellige kilder af lokalt forhandlede typer af information, når diagnoser stilles i det kliniske arbejde. Tina Brix og Gitte Wind fokuserer i artiklen "Den rummelige forskningsdiagnose: Om fravær og forhandlingsrum i tilblivelsen af en diagnose" ikke på lægers men patienters praksis, når en diagnose stilles. Med udgangspunkt i forskningsdiagnosen Bodily Distress Syndrome (BDS), der er en betegnelse for medicinsk uforklarede symptomer af kronisk karakter, og som endnu kun stilles i forskningsøjemed, undersøger Brix og Wind, hvordan en gruppe mennesker diagnosticeret med BDS forvalter og begår sig i det forklaringstomrum, der eksisterer ved en diagnose, der er karakteriseret ved en ikke-synlighed, og som dermed også bliver til i et fravær af forklaringer. Et større makroperspektiv anlægger Pia Ringø i artiklen "Skidt med årsagen, når bare vi er pålidelige: Psykiatriske diagnosers historiske udvikling, indhold og funktion". I artiklen spørger Ringø, hvilken måde psykiatriske diagnoser reflekterer grundlæggende økonomiske, politiske og samfundsmæssige transformationsprocesser. Gennem en historisk analyse af psykiatriske diagnosers status svarer Ringø på de opstillede spørgsmål om, hvordan diagnoser afspejler bevægelser i viden om og synet på menneske, samfund og sygdom. Marie Østergaard Møller introducerer os i artiklen "Magten $i$ sundhed: Om sundhedsprofessionalisme $i$ kommunale sundhedshuse" for, hvordan strukturreformen i 2007 har haft betydning for udviklingen af 
sundhedsprofessionalisme i kommunale sundhedshuse. Møller undersøger således, hvordan sundhedsprofessionalisme udøves i fraværet af læger, diagnoser og den biomedicinske forståelsesrammet fra hospitalets kliniske rammer. Det institutionelle aspekt af diagnosers status bliver ligeledes analyseret i Claus Bossens, Peter Danholts og Morten Bonde Klausens artikel "Diagnoser som styringshybrider. Diagnoserelaterede grupper $i$ sundhedsvæsenet". Med udgangspunkt i systemet DRG, Diagnose-Relaterede Grupper, der knytter patienter og deres behandlingsomkostninger sammen i faste kategorier med henblik på at måle hospitalers produktivitet, viser Bossen et al, hvordan diagnoser indgår som centrale komponenter i en styrings-infrastruktur på sundhedsområdet. Herfra vender vi blikket mod både den personlige og institutionelle anvendelse af diagnoser med Nichlas Permin Berger og Katrine Schepelern Johansens artikel "Jagten på en ADHD-diagnose: Analyse af situationer og kontekster, hoor det bliver attraktivt at være psykisk syg." Ud fra feltstudier i Kriminalforsorgens institu- tioner og i stofmisbrugsbehandlingsinstitution undersøger Berger og Johansen, hvordan en ADHD-diagnose kan blive attraktiv for professionelle og klienter med stofmisbrug, og forfatterne argumenterer for, at diagnosen anvendes som ressource i de indsattes identitetsarbejde, hvor stigma og afvigelser transformeres til sygdom, som kan behandles gennem brug af lovlig medicin fremfor illegale stoffer. I artiklen "Gir pålitelige tegn gyldige diagnoser? Den psykiatriske revolusjonen og bruk av diagnoseverktøyet SCID på en massemorder" undersøger Thomas Dahl nogle af konsekvenserne af reformen af den diagnostiske manual DSM i 1980 og udviklingen af diagnoseværktøjet SCID I. Dahl problematiserer både det epistemologiske og ontologiske grundlag for reformen, og han viser, ud fra en gennemgang af de psykiatriske undersøgelser af massemorderen Anders Behring Breivik, svaghederne ved SCID og tænkningen bag diagnosesystemet. Temanummerets sidste bidrag er essayet "Depression - giver diagnosens sprog os den bedste forklaring?" af Anita Ulrich. Ulrich argumenterer for, at videnskabens forståelse af depression overordnet består af en psykiatrisk forståelse, der søger forklaringer i biologiske vilkår, og en samfundsvidenskabelig forståelse, der peger på kulturelle og sociale årsager til depression. Herudover findes desuden, hvad Ulrich kalder, en "hverdagsdiskurs", der ikke udelukkende forbinder depression med "det sygelige", og som tilbyder alternative perspektiver til de dominerende forståelser af depression. 


\section{Referencer}

Ahlzén, R; Evans, M; Louhiala, P; Puustinen, R (eds) (2010): Diagnosis. Radcliffe Publishing, Oxford, New York.

Andersen, R. S., Tørring, M. L., \& Vedsted, P. (2014). Global healthcare seeking discourses facing local clinical realities. exploring the case of cancer. Medical Anthropology Quarterly

Anspach, R.R. (2011): »Preface«, i P.J. McGann \& D.J. Hutson (red.) Sociology of Diagnosis Bingley: Emerald Group.

Aronowitz, Robert (1998): Making Sense of Illness. Cambridge University Press

Aronowitz, Robert (2001): When do symptoms become a disease? Annals of Internal Medicine, 134: 803-8 http://dx.doi.org/10.7326/0003-4819-134-9_Part_2-200105011-00002

Brinkmann, S. (2014). Languages of suffering. Theory and Psychology 24(5):630-648. http://dx.doi.org/10.1177/0959354314531523

Davies, J. (2016): How Voting and Consensus Created the Diagnostic and Statistical Manual of Mental Disorders (DSM-III). Anthropology \& Medicine, 1-15. http://dx.doi.org/10.1080/13648470.2016.1226684

Jutel, A. (2009). Sociology of diagnosis: A preliminary review. Sociology of Health and Illness. 31(2), 278-299. http://dx.doi.org/10.1111/j.1467-9566.2008.01152.x

Jutel, A. (2011). »Sociology of diagnosis: A preliminary review«, i P.J. McGann \& D.J. Hutson (red.) Sociology of Diagnosis. Bingley: Emerald Group.

Kaufert, P. (1988) Menopause as Process or Event : The Creation of Definitions in Biomedicine. I: Biomedicine Examined, eds. M. Lock \& D.R. Gordon, 331-49. Dordrecht : Kluwer Academic Publishers

McGann \& D.J. Hutson (red.) Sociology of Diagnosis. Bingley: Emerald Group.

Mol, A. (2002): The body multiple: ontology in medical practice. Duke University Press. http://dx.doi.org/10.1215/9780822384151

Petersen, A. (2015): Omkring Diagnosekulturen: Depression som seismograf for samtiden. Dansk Sociologi. Vol. 26: 8-25.

Reventlow S, Bang H (2006): Brittle bones: Ageing or threat of disease. Exploring women's cultural models of osteoporosis. Scandinavian J of Publ. Health, 34, 320-326.

Reventlow S, Jensen HL, Sångren H. (2008): Klassifikation og oplevelse af kronisk sygdom. Patientens møde med medicinsk teknologi - vejen mod kronisk sygdom. Tidsskrift for Forskning i Sygdom og Samfund, 9: 17-31

Rosenberg, C.E. (2002). The tyranny of diagnosis: specific entities and individual experience. Milbank Quarterly, 2: 237-260. http://dx.doi.org/10.1111/1468-0009.t01-1-00003

Smith-Morris, C. (ed.) (2016): Diagnostic Controversy: Cultural Perspectives on Competing Knowledge in Healthcare. Routledge Studies in Anthropology. New York: Taylor \& Francis I P.J. McGann \& D.J. Hutson (red.) Sociology of Diagnosis. Bingley: Emerald Group.

Willadsen, T. et al (2016): The role of diseases, risk factors, and symptoms in the definition of multimorbidity - a systematic review. Scandinavian Journal of Primary Health Care, 2:112-21 
http://dx.doi.org/10.3109/02813432.2016.1153242 